\title{
La Revolución Rusa en el espejo de la larga duración
}

\begin{abstract}
Carlos Antonio Aguirre Rojas ${ }^{1}$
"Nuestra Revolución [Rusa]... será ante la historia universal grande e invencible, pues por primera vez no es una minoría, no son solo los ricos, no son únicamente los cultos, sino la verdadera masa, la inmensa mayoría de los trabajadores, quienes crean por

sí mismos una vida nueva...".

Vladimir llich Lenin, Carta a los obreros norteamericanos, 20 de agosto de 1918.
\end{abstract}

\section{Un pasado todavía muy presente}

En contra de lo que afirma la concepción positivista de la historia, hoy todavía dominante en amplios espacios del mundo académico en general, ni las supuestas "fronteras" entre el presente y el pasado son claras, nítidas y bien delimitadas, ni tampoco el pasado, supuesto objeto de estudio de la historia, es algo ya terminado, muerto y completamente cerrado y clausurado.

Por eso, mientras que Marc Bloch relativiza, cuestiona y complejiza la relación pasado-presente, llegando incluso a afirmar retadoramente que en cierto sentido el presente no existe, y que solo existen diversos pasados, como el pasado inmediato, el pasado reciente, el pasado cercano y distintos pasados menos o más lejanos, por su parte Walter Benjamin va a recordarnos que en la densa textura del presente existen siempre diferentes "pasados vencidos", que aunque no son dominantes ni vigentes, se encuentran sin embargo vivos y presentes, aunque sea de un modo latente, marginal o subordinado a los "pasados vencedores" que hoy se han convertido en el presente dominante 2 .

Pasados vencidos que pueden permanecer ocultos, subterráneos y semidormidos durante décadas y siglos, para emerger e irrumpir de pronto con fuerza en ciertos momentos especiales de la historia, en los "instantes

1 Mexicano, Doctor en Economía. Instituto de Investigaciones Sociales, Universidad Nacional Autónoma de México, México. E-mail: aguirrec@unam.mx

2 Sobre estas ricas reflexiones críticas en torno a la relación pasado-presente, cfr. Bloch (1996), en especial "La Primera Redacción", y también Benjamin (2004). Sobre los perfiles intelectuales más generales de Marc Bloch y Walter Benjamin, véase Aguirre Rojas (2015), capítulos 2 y 4 . 
de peligro" del drama histórico que son, por ejemplo, las etapas de agudas crisis generales, o también los vastos procesos de revolución social. Lo que implica que el vínculo de cada "presente" con los múltiples "pasados" que le anteceden, no sea para nada lineal ni sucesivo, sino más bien complejo y selectivo, vinculando cada presente solo con ciertos y determinados pasados, no necesariamente inmediatos ni cercanos, sino a veces lejanos, y siempre específicos y complejamente articulados.

Además, es sabido que el presente nunca "recupera" el pasado de una manera neutra, ni tampoco aséptica y desinteresada, sino que siempre lo reconstruye e interroga de modo selectivo y sesgado, es decir, desde su propia identidad y situación, desde sus propios problemas y encrucijadas, para encontrar en ese pasado respuestas, e indicios, o pistas, a esos dilemas o cuestiones actuales, e incluso hasta elementos de legitimación o de justificación de ese mismo presente. Lo que sin embargo no significa, como pretenden las absurdas e irracionales posturas de las concepciones postmodernas de la historia, que no existen verdades históricas, y que no haya un progreso real y sucesivo en el conocimiento realmente científico del pasado y del presente humanos.

Partiendo entonces de estas importantes lecciones de la historiografía crítica sobre la compleja relación entre presente y pasado, queremos abordar la significación histórica y actual de la Revolución Rusa de 1917, para preguntarnos qué es lo que sigue vivo y actuante de esta Revolución Rusa en el presente, a cien años de su saludable irrupción, pero también qué es aquello que ya ha sido superado o rebasado de la misma, siendo ahora claramente inactual. Y también para reflexionar cuáles lecciones podemos derivar, tanto en positivo como en negativo, de esta fundamental experiencia histórica, de sus intentos, de sus logros, de sus fracasos y de sus distintos resultados, lecciones que también incluyen algunos elementos que aportan pistas, para enfrentar los retos y los problemas más contemporáneos de nuestro más actual presente.

Para responder a estas preguntas de un modo inteligente, pensamos además que es útil resituarlas dentro de la óptica compleja de la teoría braudeliana de los diferentes tiempos históricos, y especialmente, de los horizontes de la larga duración histórica, lo que nos permitirá evaluar los impactos y el significado profundo de esas realidades que constituyen a la Revolución Rusa, dentro de los diversos registros temporales que, en su conjunto, conforman la compleja trama de su historia específica ${ }^{3}$.

3 Sobre esta óptica braudeliana de los diferentes tiempos históricos y de la larga duración, cfr. Braudel (1991), y también Aguirre Rojas, 1996 y 2003. 


\section{Un balance global: una derrota inmensamente victoriosa}

Según una anécdota histórica debatida, y de la que existen distintas versiones, Henry Kissinger le preguntó a Chou En Lai en 1972, durante la visita de Richard Nixon a China, que cuál era su opinión sobre los impactos históricos de la Revolución Francesa, a lo que Chou En Lai respondió, después de un breve silencio, que "tal vez era aún demasiado pronto para poder evaluarlos". Más allá de la exactitud o no de esta anécdota, la misma resulta útil cuando intentamos hacer un balance global de los impactos históricos y de la posible vigencia actual de la Revolución Rusa de 1917, y en particular, vista desde el prisma de la larga duración histórica.

Pues como es bien sabido, las estructuras de larga duración son siempre realidades cuya vida histórica trasciende a más de un siglo, mientras que esa Revolución Rusa de 1917 está cumpliendo apenas cien años de existencia. Por eso, quizá es aún demasiado pronto para evaluarla. Sin embargo, y si resituamos a esta Revolución Rusa de 1917 dentro de la familia de las grandes revoluciones sociales de los últimos cuatro siglos, podremos intentar algunos ejercicios comparativos que nos permitan discriminar, dentro de esa Revolución Rusa, aquellos elementos y procesos que anclan su existencia en el registro de la verdadera larga duración, frente a aquellos otros que han sido solamente coyunturales, o incluso, exclusivamente confinados al ámbito de los acontecimientos inmediatos.

Si observamos entonces el conjunto de revoluciones sociales que han sucedido en el mundo en los últimos cuatro siglos, nos es fácil comprobar que, al igual que la Revolución Francesa de 1789, también la Revolución Rusa de 1917 posee tanto un claro significado histórico-universal, como también y vinculado a ello, un evidente carácter modélico ejemplar. Porque mientras que otras grandes revoluciones sociales tienen solo un impacto nacional, o regional, o incluso continental, y también una vigencia histórica más limitada o puntual, en cambio la Revolución Francesa de finales del siglo XVIII, o la Revolución Rusa de la segunda década del siglo XX, sí han logrado tanto una irradiación e influencia realmente planetarias, como también una permanencia y vigencia mucho más prolongada y extendida ${ }^{4}$.

4 En esta línea de reflexión, resulta interesante revisar el ejercicio comparativo que Marx realiza entre la Revolución Inglesa de 1648, la Revolución Francesa de 1789, y la Revolución Prusiana de 1848, afirmando la significación histórico-europea de las dos primeras, frente al carácter limitado y local de la tercera, cfr. su artículo, sin título, incluido en la Nueva Gaceta Renana, núm. 169, del 15-XII-1848, incluido en Marx y Engels (2006: 374-379). Por nuestra parte, pensamos que Marx tiene razón respecto a la Revolución Inglesa, cuyo significado profundo es de escala histórico-europea, mientras que el significado de la Revolución Francesa es 
Porque es claro que durante todo el siglo XIX histórico, que va desde 1789 hasta 1914-1917 aproximadamente, la Revolución Francesa ha servido de inspiración y de modelo para múltiples revoluciones sociales a todo lo largo y ancho del mundo, mientras que en el "breve siglo XX histórico", que corre desde 1914-17 hasta 1989-94, es en cambio la Revolución Rusa de 1917 la que alimenta y sirve de referente modélico a una buena parte de las revoluciones sociales antiimperialistas, nacionalistas, o socialistas, de también todo el globo terráqueo.

Aunque con una profunda diferencia entre estas dos revoluciones mencionadas, diferencia derivada de su propio momento de surgimiento e irrupción. Pues mientras que la Revolución Francesa de 1789 es el proceso de coronamiento y de consolidación de todos los cambios económicos, sociales, políticos y culturales que vive la sociedad europea desde el siglo XVI, y que alcanzan su punto de clímax a mediados del siglo XIX, en cambio la Revolución Rusa de 1917 tiene en esencia un carácter más bien anticipatorio y premonitorio de los cambios y de las experiencias por venir. Cambios e intentos de superar radicalmente y de trascender profundamente al capitalismo mundial, que llenan toda la historia de ese breve siglo XX, para prolongarse incluso hasta la época actual.

Diferencia clara entre la Revolución Francesa de 1789 y la Revolución Rusa de 1917, que se vincula a la divergencia radical entre la primera, que fue una revolución burguesa o democrático-burguesa, y de otra parte la segunda, la que intentó ser consciente y explícitamente una revolución proletaria o socialista, lo que sin duda logró durante aproximadamente una década, mientras Lenin estuvo vivo y un poco más allá, para después irlo perdiendo, trágica y progresivamente, a todo lo largo del breve siglo XX. Divergencia entre las revoluciones burguesas y la revolución proletaria, a la que muy claramente aludió Marx en su obra de El 18 brumario de Luis Bonaparte, que explica también los diversos ciclos históricos de vigencia, tanto de la Revolución Francesa como de la Revolución Rusa que aquí comparamos.

Así, en lo que parecería una cierta carrera de relevos histórica, es posible reconocer que si todas las grandes revoluciones del largo siglo XIX toman como su modelo a la Revolución Francesa de 1789, en cambio, todas las grandes revoluciones del breve siglo XX tendrán como su referente principal a la Revolución Rusa de $1917^{5}$. Pero del mismo modo en que la función modé-

de alcance histórico-universal, aunque esta dimensión histórico-universal se desplegará precisamente, solo después de la escritura de este texto de Marx. Así, por ejemplo, la Revolución Mexicana de 1910, o la Revolución Cubana de 1959, son de alcance o significado histórico-latinoamericano, y la Revolución China de 1949 es de alcance fundamentalmente histórico-asiático, (aunque la Revolución Cultural China de 1966-69, sí posee en cambio una dimensión histórico-universal), por citar solo algunos de los muchos ejemplos posibles.

5 Por eso, lo mismo todas las revoluciones de 1848 en Europa, que la Revolución Mexicana de 1910, o la Revolución China de 1911, han tenido como modelo a la Revolución Francesa, 
lica de la Revolución Francesa se agotó después de 1917, así también parece haberse extinguido el carácter modélico de la Revolución Rusa después de la caída del Muro de Berlín, y también de la lamentable reconversión completa de Rusia en uno más de las decenas de países actualmente capitalistas del orbe.

Y aunque ahora, a cien años de la Revolución Rusa de 1917, no parece existir todavía una nueva revolución que funcione como paradigma o modelo histórico-universal para las nuevas revoluciones sociales por venir, sí es claro en cambio que lo más cercano a este modelo de las nuevas formas de hacer una nueva revolución social, que sea no sólo genuinamente anticapitalista, sino también genuinamente antisistémica, se encuentra en la rica y compleja experiencia del movimiento neozapatista mexicano. Lo que, entre muchas otras razones, tal vez explique la irradiación y la atención planetaria, permanente y creciente, que este neozapatismo ha suscitado y suscita desde hace más de veintitrés años y hasta el mismo día de hoy. ${ }^{6}$

Entonces, si el impacto histórico-universal de la Revolución Rusa en tanto modelo de otras revoluciones sociales radicales se despliega a lo largo de todo el breve siglo XX, para extinguirse con la caída del Muro de Berlín y con el fin mismo de ese breve siglo XX, debemos preguntarnos ahora si esa Revolución Rusa de 1917 triunfó o fracasó. Y para responder a esta pregunta simple, que intenta aprehender a una realidad compleja, debemos responder con una respuesta también compleja, que es la de que esa Revolución Rusa fracasó y triunfó al mismo tiempo. Es decir, fracasó en varios sentidos, pero triunfó también en muchos otros sentidos importantes.

Lo que todavía en un plano general y abstracto, que concretaremos y particularizaremos más adelante, significa que efectivamente la Revolución Rusa fracasó en cuanto al objetivo general que se había planteado ella misma, y que era un objetivo enorme y fundamental, de destruir radicalmente el capitalismo, primero en Rusia y luego en todo el mundo, para en su lugar edificar una nueva sociedad comunista sin explotación económica, sin clases

mientras que las revoluciones del siglo XX cronológico, en Argelia, o en Cuba, o en Chile, o en China, o en Europa Oriental, se inspiraban claramente en la Revolución Rusa. E incluso Lenin dirá que en su primera etapa y como su primera tarea, la propia Revolución Rusa de 1917, "se asignó como tarea directa e inmediata un objetivo democrático-burgués", y que ellos han "llevado la revolución democrático-burguesa a su término, como nadie", e incluso más radicalmente que la propia "Gran Revolución Francesa", afirmando además, muy clara y proféticamente, que "solo la lucha decidirá en qué grado conseguiremos... avanzar" hacia la "revolución socialista". Lo que como veremos más adelante, se logró solo en parte y sólo temporalmente, aunque con un gran impacto de alcance histórico-universal y de duración de más de medio siglo. Cfr. Vladimir llich Lenin, "Con motivo del Cuarto Aniversario de la Revolución de Octubre", del 14-X-1921, en Lenin (s/f: 654-655).

6 Sobre esta irradiación planetaria, y sobre el significado histórico-universal del neozapatismo, cfr. Immanuel Wallerstein (2008: 214-245) y Aguirre Rojas, 2012 y 2014. 
sociales ni desigualdad social, sin Estado, y sin jerarquías ni discriminaciones culturales o sociales de ningún tipo. En alcanzar este magno objetivo anticapitalista autoasignado, la Revolución Rusa no tuvo éxito.

Pero en cambio esa Revolución Rusa significó un inmenso triunfo, tanto en lo que se refiere a cambiar positivamente el destino y el papel histórico de Rusia en el mundo, durante el breve siglo XX, como también respecto de la ya evocada función de paradigma o modelo que ella jugó para todas las grandes revoluciones sociales posteriores a 1917 y anteriores a 1989 y 1994.

En primer lugar, ese éxito enorme se ilustra en el modo en que la Revolución de 1917 cambió, para siempre y sin retorno, el destino histórico de Rusia en todo el siglo XX. Pues gracias a esa revolución, Rusia pudo modernizarse, urbanizarse, industrializarse, alfabetizarse integralmente y desplegar un excepcional desarrollo social, político y cultural de toda su población, lo que le permitió, entre muchas otras cosas, lanzar un hombre al espacio antes que ninguna otra nación, a la vez que acumulaba el segundo arsenal militar del planeta y se convertía en la segunda superpotencia del mundo, compitiendo en condiciones de igualdad con Estados Unidos en los más diversos campos económicos, sociales, políticos y culturales, pero también deportivos, científicos, artísticos, de la carrera espacial o hasta del ajedrez mundial.

Inmenso desarrollo de la sociedad rusa soviética, que si bien no era un desarrollo comunista o anticapitalista, sino más bien de un potente capitalismo de Estado -Capitalismo de Estado que, por lo demás, fue explícitamente previsto como uno de los posibles futuros de la Revolución Rusa por el propio Lenin-, le permitió a Rusia salir del atraso, la miseria y el pobre desarrollo social general que mantuvo durante todo el régimen zarista hasta 1917, para convertirla en la segunda superpotencia del globo terráqueo en el siglo XX. Un argumento, este último, que le gustaba repetir a Fernand Braudel, al proponer que se compararan los itinerarios históricos durante el siglo XX, de un lado de la India siempre capitalista, y del otro de Rusia o de China, ambas hijas de profundas revoluciones sociales, que durante un cierto periodo intentaron caminar por la vía socialista o comunista․

7 Por eso Braudel (1978: 220-228) pregunta provocativamente al lector, si para avanzar realmente como sociedad y lograr cambios importantes a nivel económico, social y político, " ¿Es necesario que la India realice una revolución de tipo chino?", es decir, una revolución socialista, como la de Rusia en 1917 o la de China en 1949. Proyectando este mismo razonamiento hacia América Latina, podríamos decir que si hoy Cuba no es un país como Haití, eso es gracias a la Revolución Cubana, pues igual que el grado de desarrollo de Cuba y de Haití era similar antes de 1959, así era similar el grado de desarrollo de Rusia, China e India a comienzos del siglo XX. 
Pero también y en segundo lugar, la Revolución Rusa triunfó enormemente, al convertir a Rusia durante el breve siglo XX que va de 1917 a 1989, no solo en un actor geopolítico de primer nivel en escala planetaria, solo comparable con Estados Unidos, sino también en el país líder de lo que durante varias décadas, desde 1945 y hasta los años ochenta del siglo $X X$, se llamó el "segundo mundo" o mundo socialista, igual que en el caso modélico de inspiración de la inmensa mayoría de las grandes revoluciones sociales anteriores a 1989. País líder y modelo inspirador, que no fueron solo ideas abstractas sino también hechos muy concretos, pues la Unión Soviética, a través de la Tercera Internacional y de los Partidos Comunistas de todo el mundo, intervino de muy diversas maneras, no siempre acertadas ni progresistas, en la gran mayoría de los procesos de cambio social radical y en los movimientos revolucionarios del planeta entero.

Por eso, la Revolución Rusa de 1917 triunfó fracasando, o construyó desde su propia derrota, también inmensas victorias. Tesis paradójica pero real, que para ser mejor comprendida, requiere que pasemos ahora a un análisis más específico y particularizado de las diversas etapas o coyunturas históricas que atravesó esa revolución rusa a lo largo del breve siglo XX.

\section{Legados en claroscuro: revoluciones y contrarrevoluciones rusas en el breve siglo XX}

Marx, en alguna de sus referencias célebres sobre la Revolución Francesa, dice que una de las funciones centrales de ella fue la de crear el Estado burgués por excelencia, y también la forma clásica y adecuada del sistema político moderno-burgués, en su expresión más pura y acabada. Y en alguna otra ocasión, también agrega que la función histórica de Napoleón y del Imperio Napoleónico, fue la de barrer y eliminar en toda Europa los resabios feudales todavía existentes, para abrir el espacio del desarrollo sin trabas de la moderna sociedad burguesa en todo el territorio europeo.

Haciendo un símil con estas caracterizaciones de Marx, y a la luz de los cien años transcurridos desde 1917, podríamos decir que una de las funciones centrales de la Revolución Rusa fue la de crear, bajo las huellas de la Comuna de París de 1871, y por un breve periodo histórico, la estructura de gobierno de los Consejos o Soviets en una escala nacional, es decir, la primera forma de alcance histórico-nacional del autogobierno popular, basado en la democracia directa y en el protagonismo central de las Asambleas. Y podemos también agregar que la función del régimen estalinista, fue la de barrer en toda la Unión Soviética los resabios precapitalistas todavía existentes, para abrir el espacio del desarrollo libre y sin trabas de un potente capitalismo de Estado dentro de la Unión Soviética. 
Para entender mejor este símil propuesto, vale la pena revisar cuáles han sido las diversas coyunturas o etapas históricas que vivió esa Revolución Rusa durante el último siglo transcurrido. Y esas coyunturas son, en nuestra opinión, cuatro. Y a esas cuatro coyunturas, que tienen impactos e irradiaciones históricas muy diferentes entre sí, se asocian también, en consecuencia, legados y herencias muy diversos.

Así, la primera coyuntura es la de la Revolución Rusa bajo Lenin, que inicia en 1917 y que se va apagando progresivamente después de su muerte, durante los años veinte del siglo XX. Esa coyuntura está directamente vinculada al legado histórico del leninismo, un legado que es tanto práctico como teórico, y que tendrá un impacto histórico-universal y una vigencia que, aunque de manera desigual, se prolonga hasta el día de hoy.

Después viene la coyuntura de la Revolución Rusa bajo Stalin, que inicia a finales de los años veintes del siglo pasado, y concluye con la muerte de Stalin en 1953. Y ahora, a más de medio siglo de su conclusión, es claro que el legado del estalinismo fue solamente de orden práctico, y que aunque tuvo en su momento un impacto también histórico-universal, este impacto se extinguió con la propia muerte de Stalin.

Finalmente, se suceden las dos coyunturas sucesivas a la muerte de Stalin, la primera que va de 1953 a 1991, y la segunda de 1991 hasta hoy, y en ambas se trata claramente de la progresiva decadencia del capitalismo de Estado ruso, el que hasta 1991 se va degradando y debilitando para colapsar y desaparecer después de la caída del Muro de Berlín y de la Perestroika, abriendo paso, desde hace un cuarto de siglo, a la reimplantación de un capitalismo privado y tradicional en todos los territorios de la antigua Unión Soviética, hoy llamada Confederación de Estados Independientes. Y es claro que durante la coyuntura de 1953 a 1991, la Revolución Rusa va perdiendo poco a poco su influencia y su impacto mundiales, haciendo de esa era postestalinista un fenómeno cada vez más exclusivamente ruso, de impacto solo nacional, y si acaso de influencia hacia las naciones directamente contiguas a Rusia, primera etapa o coyuntura postestalinista cuyo legado es solo vigente para esa misma Rusia, y mucho más limitado en términos temporales.

Lo que se hace muy evidente en la cuarta coyuntura o etapa, después de 1991, cuando Rusia es el último invitado, semiforzado, del G-7 (que por su inclusión se convierte en G-8), y cuando su papel geopolítico se reduce notablemente, para ser ahora equiparable al de cualquiera de los otros miembros del grupo de países de los llamados BRICS, de China, de India, de Sudáfrica o de Brasil. Revisemos ahora, más detenidamente, estas cuatro coyunturas de la Revolución Rusa de 1917 y sus diferentes legados, a veces fundamentales, y a veces muy limitados o hasta inexistentes, para el mundo de hoy. 
La primera coyuntura, que va desde 1917 hasta finales de los años veinte del siglo XX, posiblemente hasta más o menos 1927 o $1928^{8}$, está claramente asociada a la figura y a la obra de Lenin y del leninismo. Y ella ha tenido un impacto tanto práctico como teórico, ambos de dimensiones históricouniversales y de una vigencia que, con altibajos, sigue viva y actuante hasta el día de hoy. Y es el conjunto de legados y herencias derivados de esta primera coyuntura o etapa, lo que ha determinado que la Revolución Rusa alcance la misma estatura histórica y modélica de la Revolución Francesa, para servir de paradigma a la mayoría de las grandes revoluciones sociales del breve siglo XX, y para continuar aun hoy siendo una fuente importante de ciertas lecciones, aún válidas, para los actuales movimientos anticapitalistas y antisistémicos de todo el planeta.

Pues en primer lugar, y durante la última etapa de vida de Lenin, e incluso unos pocos años después de su muerte, la Revolución Rusa representó una experiencia práctica riquísima y compleja de intento de construcción de una sociedad nueva no capitalista, solo comparable en la magnitud de ese objetivo, con la también excepcional experiencia de la Comuna de París de 1871. Pero mientras que la Comuna tuvo solo la dimensión de una gran ciudad de un millón de habitantes, y duró funcionando como gobierno solo 73 días, en cambio la Revolución Rusa de 1917, en esa primera etapa de vida suya, profunda y genuinamente anticapitalista, funcionó en la escala de un inmenso país, que es el país más grande del planeta, y además durante aproximadamente una década entera.

Y durante esa década gloriosa, en la entonces naciente Unión Soviética, sucedieron cosas tan extraordinarias y radicales como la de abolir el dinero, o la de expropiar toda la tierra a todos los terratenientes y todas las fábricas a todos los capitalistas, o la de reubicar a los pobres de las ciudades en las casas de los ricos, o la de darle todo el poder social y político a los Soviets o Asambleas, o Consejos de Obreros, Campesinos y Soldados, en todo el territorio ruso, o comenzar en los hechos y efectivamente a desmantelar la estructura misma del Estado, o crear la legislación sobre los derechos de las mujeres más avanzada del mundo en ese momento, o también la de confrontar o combatir radicalmente el oscurantismo religioso y la perniciosa influencia de la Iglesia sobre las clases populares.

8 Proponemos de manera conjetural estas fechas, pues es claro que todos los procesos impulsados por Lenin durante los primeros seis años de la Revolución Rusa, no se cancelan automáticamente a partir de enero de 1924, sino que van siendo modificados poco a poco, o decaen lentamente, o son abandonados en un cierto momento, etc., hasta terminar por desaparecer totalmente. Sobre estos procesos de eclipse del proyecto impulsado por Lenin, y de afirmación del muy diverso proyecto de Stalin, aunque referido sobre todo a la economía y a la política, véase Bettelheim, 1977 y 1979. 
También, y vinculado a este inmenso intento práctico de superar al capitalismo en los hechos, y de crear realmente una nueva sociedad no capitalista, es que se desarrollaron los ricos debates sobre la vigencia de la ley del valor y sobre una posible acumulación socialista, junto al desarrollo de una nueva pedagogía revolucionaria, y de una liberalización radical de las costumbres y de los hábitos sexuales, paralelamente a los intentos de llevar a cabo toda una profunda revolución cultural, o de construir una forma nueva del poder social, el poder soviético, al mismo tiempo en que se debatía sobre los modos de revolucionar totalmente la vida cotidiana misma de esa nueva sociedad socialista naciente. ${ }^{9}$

A partir de todos estos procesos, la Unión Soviética de 1917-1927/28 se convirtió en un inmenso y excepcional laboratorio de experimentación social de cómo intentar destruir y enterrar totalmente al capitalismo, pero también y sobre todo, de cómo tratar de edificar una sociedad nueva, ya no capitalista, sin explotación económica, sin clases sociales, sin Estado, y sin jerarquías culturales y sociales en general. Inmenso y grandioso experimento de cambio social radical, intentado por los pueblos soviéticos, que terminará fracasando por la tragedia histórica de que ni la revolución europea ni tampoco la revolución mundial pudieron en esos tiempos secundar y apoyar a la Revolución Rusa. Pero también y conectado con esto, por la consolidación, no del socialismo sino del capitalismo de Estado, que se desarrollará en la URSS durante todo el periodo de gobierno de José Stalin.

Y sin embargo, y más allá de esa involución histórica de la Revolución Rusa bajo el stalinismo, es un hecho que toda la experiencia histórica desplegada por el pueblo ruso entre 1917 y 1927-28, sigue siendo hasta hoy una cantera enorme de lecciones prácticas, de cómo intentar construir una economía, una sociedad, una política y una cultura no capitalistas, cantera que ha alimentado y alimenta a los movimientos revolucionarios y anticapitalistas, y a los intentos de revolución social, de los últimos cien años y hasta hoy.

Lo que, por mencionar un solo ejemplo entre muchos posibles, se ilustra en el hecho de que existe una clara línea de continuidad histórica evidente entre la Comuna de París de 1871, el poder soviético de 1917-1928, los intentos, aunque no exitosos sí fundamentales, de los Consejos Obreros

9 Para tener idea de la magnitud de este excepcional laboratorio de cambio social radical que fue la Unión Soviética entre 1917 y 1928, y sólo a título de algunos de los muchos ejemplos posibles, citamos en el mismo orden enunciado en el texto, sobre los debates económicos, Preobrazhensky (1971), y Lenin (et al.) (1974), sobre la revolución pedagógica, Semionovich (1996), sobre la revolución sexual, Reich (1970), sobre la revolución cultural, Lenin (s/f: 778-785), sobre el poder soviético, Vladimir llich Lenin, "Con motivo del cuarto aniversario de la Revolución de Octubre", ya antes citado, y sobre la revolución de la vida cotidiana, Trotsky, 1971. 
alemanes, húngaros o italianos, las Guardias Rojas de la Revolución Cultural China, y en la actualidad, las Juntas de Buen Gobierno Neozapatistas, los procesos de autogobierno de ciertos barrios piqueteros autonomistas argentinos, o la actividad cotidiana de las bases -pero no de los líderes- del Movimiento de los Sin Tierra brasileños, por mencionar sólo algunos de los muchos ejemplos posibles. ${ }^{10}$

Experimento práctico de impacto histórico-universal y de larga vigencia histórica, que fue esta primera década de la Revolución Rusa, que se cerrará cuando Stalin comience a desmantelar el poder de los soviets para fortalecer en cambio al Estado ruso, y cuando imponga desde arriba y por la vía de la violencia la colectivización forzosa del campo ruso, pero también cuando clausure los procesos de la revolución sexual y de la revolución cultural iniciados en 1917, y cuando consolide de modo definitivo la restauración del capitalismo en la URSS, bajo la modalidad de un potente capitalismo de Estado ${ }^{11}$. Y todo ello, acompañado de la postulación y la defensa de la tesis de la legitimidad y de la posibilidad real de construir "el Socialismo en un solo país".

Porque debemos insistir en que la tesis del socialismo en un solo país no es de Lenin, quien concebía que el destino final de la Revolución Rusa dependía, en gran medida, de la irrupción de la revolución mundial ${ }^{12}$, sino que es una invención de Stalin para justificar el camino de la restauración capitalista que tomó la Revolución Rusa bajo su propio gobierno. Pero esta tesis de Stalin, va en contra de la propia idea de Marx, expresada en el capítulo primero de La Ideología Alemana, en donde niega la posibilidad de una revolución

10 Sobre este argumento, que aquí solamente resumimos y mencionamos, cfr. Aguirre Rojas, 2011 y 2009.

11 Vale la pena recordar aquí el hecho de que Lenin, al plantear la necesidad del viraje importante que representó la NEP, la Nueva Política Económica, es muy consciente de que se trata de un "repliegue económico", que promueve en la URSS no el socialismo sino el capitalismo de Estado. Pero Lenin concibe que este repliegue es posible, e incluso positivo, porque según su concepción la NEP será algo claramente temporal, y porque estará permanentemente bajo el control del poder realmente soviético, cfr. sobre estos puntos, su texto "Sobre el Impuesto en especie", en Lenin (s/f: 601-634). Pero cuando Stalin desmantela el poder soviético, y en su lugar consolida al Estado ruso, y cuando revierte la mayoría de los procesos radicales anticapitalistas de la revolución social en la URSS, iniciados en 1917, abre entonces claramente la vía a la consolidación y afianzamiento del capitalismo de Estado en la URSS, y no del socialismo incipiente de la época leninista de la primera década de la Revolución Rusa. Y todo esto, más allá del destino concreto de la propia NEP.

12 Sobre esta tesis de Lenin, basta mencionar como ejemplo sus afirmaciones, cuando plantea que "Nosotros contamos con la inevitabilidad de la revolución mundial", y también al afirmar muy lapidaria y enfáticamente que "Nos encontramos como si estuviéramos en una fortaleza sitiada, en tanto no nos llegue la ayuda de otros destacamentos de la revolución socialista mundial", en "Carta a los obreros norteamericanos", en Lenin (s/f: 49- 50). Y es en parte esta no llegada de esa ayuda, la que explica también la involución histórica de la Revolución Rusa bajo Stalin, y la consolidación del capitalismo de Estado en la Unión Soviética, durante una parte importante del breve siglo XX. 
comunista en solo un país, e incluso en unos pocos países, planteando en cambio su necesaria proyección y expansión en escala mundial.

Tesis de Marx que parecería verse trágicamente confirmada por la historia de todas las revoluciones sociales del breve siglo XX, que intentaron construir en sus respectivas naciones ese "Socialismo en un solo país", como en los casos de China, de Vietnam, de todos los países de Europa Oriental, o de Corea del Norte, entre varios otros. Y que como moneda todavía en el aire, está ahora mismo en suspenso, en el heroico caso de Cuba.

Planteamiento de Marx de la Revolución Comunista, como revolución necesariamente mundial, que hoy es recuperada nuevamente por los actuales movimientos anticapitalistas y antisistémicos de todo el planeta, por ejemplo, por el neozapatismo mexicano y su inteligente iniciativa del movimiento nacional mexicano, pero también internacional, de "La Sexta". Porque si el capitalismo es un sistema de explotación y de dominio mundiales, y si como dijo Marx "Los obreros no tienen patria", entonces ese capitalismo no puede ser vencido solo a nivel nacional, sino que debe ser combatido y destruido a nivel mundial. Lo que no significa, ni mucho menos, que exista un "Palacio de Invierno" mundial a conquistar, ni que existan en todo el planeta solo dos grandes frentes mundiales, de un lado del capitalismo y del otro del anticapitalismo, pero sí significa en cambio, que ningún proyecto genuinamente anticapitalista y antisistémico tiene futuro en el mediano y en el largo plazos, si se concibe solo en escala nacional, "en un solo país", y también significa que el destino final de cualquier proyecto de transformación social radical, desplegado inicialmente en cualquier espacio local, nacional o incluso continental, depende a fin de cuentas de la eliminación planetaria, total y radical, del capitalismo mundial. Trágica lección en negativo de la Revolución Rusa, que parece no haber sido bien asimilada por los recientes gobiernos llamados "progresistas" de América Latina, los que pretenden defender un amorfo y confuso "Socialismo del siglo XXI", que de verdadero socialismo no tiene más que el nombre, y que son un conjunto de proyectos concebidos siempre en la misma y exclusiva escala nacional, que inevitablemente nos recuerda ese viejo y anacrónico modelo estalinista del "Socialismo en un solo país".

Y si las principales lecciones prácticas de alcance histórico-universal, en positivo y en negativo, de esa primera década de la Revolución Rusa, son estas que hemos referido, junto a ellas se afirman también varias lecciones teóricas, igualmente de impacto histórico-universal, aunque de desigual vigencia histórica. $Y$ todas esas lecciones teóricas se encuentran contenidas en la obra teórico-política de Vladimir llich Lenin. Y aunque es claro que la obra teórico-política de Lenin no agota toda su obra, que incluye también a sus importantes Cuadernos filosóficos, o al brillante libro El desarrollo del 
capitalismo en Rusia, o a sus diversos textos de debate económico, y también a El Imperialismo, Fase Superior del Capitalismo, también es evidente que esa teoría política leninista es el núcleo principal y el aporte esencial mayor del trabajo intelectual global de Lenin, además de ser también la que se vincula directamente a los legados teóricos de esa primera etapa de la Revolución Rusa de 1917.

Porque Lenin ha sido, incontestablemente, uno de los dos más grandes teóricos políticos marxistas de todo el siglo XX, junto con Antonio Gramsci, desarrollando en este campo de la teoría política crítica, un aporte no solo fundamental, sino también y en gran medida, vigente todavía hoy en escala histórico-universal. ${ }^{13}$ Aporte que, visto en general, se articula en torno de tres ejes o subcampos de análisis, que son la teoría del partido revolucionario, la teoría del Estado y de las relaciones políticas burguesas, y finalmente, la teoría de la revolución social radical. Revisemos ahora brevemente cada uno de estos tres subcampos, así como su impacto y vigencia histórica específicas.

La teoría del partido revolucionario, que Lenin elabora en los inicios de su carrera política, y que se plasma en textos como ¿Qué hacer? y Un paso adelante y dos atrás, es una teoría que inspiró la construcción de la inmensa mayoría de los Partidos Comunistas, e incluso de muchas organizaciones revolucionarias de todo el mundo, a lo largo del breve siglo XX desplegado entre 1917 y 1989. Pero si ella fue en lo esencial vigente, y válida y útil, hasta la Revolución Cultural mundial de 1968, después de esa fecha empezó a decaer y a ser progresivamente cuestionada, para ser completamente abandonada después de 1989 y 1994. Y esto, porque esa teoría del partido leninista reflejaba un determinado grado histórico de maduración política y de conciencia crítica del conjunto de las clases y sectores subalternos, grado que mutó radicalmente a lo largo del breve siglo XX, para hacer inoperante e inválida esta teoría leninista del partido.

Límites históricos específicos de la teoría leninista del partido revolucionario, que son intuidos ya por el propio Lenin, el que en 1917 no plantea la consigna de "Todo el poder al Partido bolchevique", sino más bien la sabia

13 Por esta razón, estamos en contra de ciertos autores que, recientemente, han creído ser muy agudos asumiendo un antileninismo superficial y muy poco seriamente fundado, que le atribuye a Lenin los errores de Stalin, y también la responsabilidad del fracaso progresivo de la Revolución Rusa. Pero estos autores sólo nos recuerdan el dicho popular ruso, citado alguna vez por el propio Lenin: "¡Bravo debe ser el faldero, cuando ladra al elefante!". En cambio, como hemos tratado de mostrar aquí, y como desarrollaremos ahora, es un hecho que las principales lecciones prácticas y teóricas, de alcance y de vigencia histórico-universal de la Revolución Rusa de 1917, se hallan todas asociadas a la obra y a la actividad práctica de Vladimir llich Lenin. 
consigna de "Todo el Poder a los Soviets", con lo cual anticipa precisamente esa mayor maduración y conciencia crítica y política de las clases populares, que hoy ha hecho inválida su propia teoría. Porque hoy, todos los movimientos genuinamente anticapitalistas y antisistémicos del mundo, han abandonado ya la forma partidaria de organización, rechazando su verticalismo, su estructura jerárquica, su excesiva centralización de decisiones y funciones, y su clara división entre dirigentes, cuadros medios y bases del partido, para en su lugar, promover formas de organización mucho más laxas y horizontales, menos jerárquicas y menos centralizadas, en donde los liderazgos son colectivos, rotativos, y siempre sustituibles inmediatamente, y en donde además de criticar el protagonismo de los verdaderos o de los supuestos "líderes", se afirma incluso que "las bases son los líderes", y que un principio esencial de la organización es el de "no hegemonizar, ni tampoco homogeneizar", ni al interior ni al exterior de los movimientos, tal y como afirman hoy sabiamente los compañeros neozapatistas en México. ${ }^{14}$

El segundo subcampo o eje del aporte teórico-político leninista, es el de la teorización del Estado burgués, y la caracterización de las relaciones políticas capitalistas. Y en esta área, Lenin va a desarrollar una contribución que hoy, en 2017, sigue siendo completamente vigente, e incluso imprescindible, para los movimientos anticapitalistas actuales. Pues por ejemplo en $E$ I Estado y la Revolución, y siguiendo las lecciones de Marx en La guerra civil en Francia, Lenin va a caracterizar la esencia del Estado moderno burgués, desmitificando la admiración ciega y acrítica de la democracia burguesa, y mostrando el carácter nunca neutro, sino siempre sesgado y opresor, de todo Estado posible, e incluso de un eventual "Estado socialista", para reivindicar radicalmente el objetivo explícito de destruir y hacer añicos el Estado burgués, pero también el objetivo más general de abolir por completo la estructura misma de todo posible Estado.

Tesis fundamental que nos recuerda que el Estado no es algo neutro, que hoy estaría ocupado por los opresores y explotadores, y por ende sería un Estado "malo", pero que mañana podría estar ocupado por los movimientos revolucionarios, o por los buenos "líderes progresistas", y que por ende se convertiría en un Estado "bueno" y defendible, sino que es siempre un instrumento construido para la opresión de una clase por otra, un aparato creado para ejercer el dominio político y el sometimiento social, y también y siempre, un instrumento de monopolización de las decisiones que corresponden a la mayoría en beneficio de una pequeña minoría, y por lo tanto, es siempre un

14 Sobre este punto importante, vale la pena revisar el texto del Subcomandante Insurgente Marcos, "La Sexta", de enero de 2013, que es parte de los comunicados de la serie "Ellos y Nosotros", en el sitio de Enlace Zapatista: http://www.ezln.org.mx. También Aguirre Rojas, 2017 y 2014. 
enemigo permanente de las clases populares y subalternas de la historia. $Y$ también, siempre, la antípoda misma del verdadero autogobierno popular, en cualquiera de sus formas o variantes. Tesis que tampoco parece haber sido todavía asumida por los diferentes gobiernos llamados "progresistas" de la América Latina contemporánea. ${ }^{15}$

Y junto a esta teoría, radicalmente crítica del Estado burgués, igual que del Estado en general, Lenin va a desarrollar también importantes y sugestivas caracterizaciones de lo que es la dictadura y de las diferentes formas de la democracia, pero también de la esencia del poder soviético y de la distinción entre Estado y gobierno, y la tesis de la esfera de la política como "economía concentrada", y la del rol político de los sindicatos, o de las cooperativas económicas, o de las diferentes vías o modos de participar en la revolución, o sobre los compromisos en política, o sobre las concesiones, pero también sobre la lucha de principios, y sobre cómo mantener siempre una lógica profundamente anticapitalista y revolucionaria en la actividad política cotidiana y en la lucha por los objetivos generales, o sobre los vínculos entre ideología y política, entre muchos otros temas y contribuciones que aun sería útil conocer, estudiar y recuperar, por parte de los movimientos antisistémicos de todo el mundo. Contribuciones esenciales que se encuentran contenidas en los más de cincuenta tomos de sus Obras Completas.

También, un tercer eje o contribución mayor de la obra leninista, es su teoría acerca de las premisas y condiciones de una revolución social radical, primero posible y luego triunfante, aunque fuese efímeramente. Teoría sobre la revolución que se condensa de manera paradigmática en su aforismo bien conocido cuando afirmó: "La ley fundamental de la revolución, confirmada por todas las revoluciones, y en particular por las tres revoluciones rusas del siglo XX, consiste en lo siguiente: (...) sólo cuando los "de abajo" no quieren y los "de arriba" no pueden seguir viviendo a la antigua, sólo entonces puede triunfar la revolución"16. Aforismo que naturalmente condensa toda una serie de textos y argumentos de Lenin, que explican cómo se llega a esta situación doble, donde los de abajo no quieren ya ser explotados, ni dominados, y plantean radicalmente su respectivo " ¡Y Ya basta!", y los de arriba ya no pueden ni explotar ni gobernar al modo antiguo, habiendo perdido el consenso y la legitimidad anteriores, situación doble a la que Lenin califica de una verdadera "crisis nacional general".

15 Para un desarrollo más amplio de este argumento, cfr. Aguirre Rojas 2013 y 2014: 73-113.

16 Véase Vladimir Ilich Lenin "La enfermedad infantil del 'izquierdismo' en el comunismo", en Lenin (s/f: 405). Véanse también, de este mismo texto, las páginas 354-55, 405-406, y 413 , sobre este mismo problema. 
Crisis nacional general, que del lado de los de arriba, de los dominadores y explotadores, es una crisis gubernamental provocada por su división y desgarramiento internos, la que confronta a esos grupos dominantes entre sí, provocando su confusión y su debilitamiento, y por lo tanto, la impotencia del gobierno, con el colapso concomitante de sus mecanismos de dominación, de sometimiento, y de reproducción de su poder en general.

Simultáneamente y del lado de los de abajo, hay una clara maduración de su conciencia política y social, la que derivada de su propia experiencia de lucha práctica, y acompañada por el trabajo heroico, firme, abnegado y lúcido de los grupos más politizados y avanzados -los que además, se apoyan en la teoría del marxismo como marco general de su análisis y de su práctica, según Lenin-, asumen la conciencia de la impostergable necesidad de la revolución, e incluso de su voluntad de sacrificar, si es necesario, su propia vida a esta necesidad. Lo que los lleva a exigir cambios radicales, y a plantearse y plantear en general que ya no quieren y no aceptan vivir al modo antiguo. Lo que nosotros, siguiendo a E. P. Thompson, podríamos traducir como el hecho de que su "economía moral" ha llegado al punto de saturación, que los lleva a asumir como intolerable el dominio y la explotación que cotidianamente ellos padecen, lo que los ubica en esa situación planteada por Lenin que aquí mencionamos ${ }^{17}$.

Teoría leninista de la revolución que, en muchas de sus tesis, sigue siendo válida y vigente hasta hoy, por ejemplo, cuando reivindica que la teoría marxista debe ser la "base de granito" que constituya el marco general de nuestros análisis y de nuestras explicaciones de la realidad ${ }^{18}$, aunque en otras de sus tesis, vinculadas por ejemplo al papel de la "vanguardia" respecto de las masas, o de ciertas estrategias o tácticas propuestas, haya también caducado, igual que su teoría del partido antes mencionada. Pero que también sigue siendo profundamente válida en su exigencia de la necesidad de pensar, siempre y permanentemente, en términos genuinamente anticapitalistas, subversivos y radicales, algo que toda la obra entera y toda

17 Sobre este fundamental concepto de la "economía moral de la multitud", y sobre sus implicaciones principales, cfr. Thompson (1995) y también "Edward Palmer Thompson y la 'economía moral de la multitud' en el mundo del siglo XXI", en Aguirre Rojas (2015).

18 En este sentido, vale la pena recordar que recientemente, en 2015, los compañeros neozapatistas también nos han recordado el hecho de que en su opinión, no es posible entender y diagnosticar lúcidamente al sistema mundial capitalista actual, a la "hidra capitalista", sin recuperar de modo central tanto la teoría del valor como también la teoría de la historia, ambas de Marx. Aunque agregando sabiamente que después es necesario ahora ir más allá de estas mismas teorías, actualizándolas con los aportes principales del pensamiento crítico de todo el siglo XX y de la actualidad. Sobre este punto cfr. el libro El pensamiento crítico frente a la hidra capitalista. Participación de la Comisión Sexta del EZLN, 2015 (Tomo I: 257-264-65, 287, 290 y 346). 
la vida y la actividad práctica de Lenin ejemplifica, de una manera aguda y paradigmática.

Como hemos planteado, la primera fase de la Revolución Rusa de 1917 a 1927-28, asociada íntimamente al legado del leninismo, tuvo un impacto tanto teórico como práctico, que fue además un impacto de carácter histórico-universal y de una larga vigencia, que a veces se prolonga hasta la Revolución Cultural Mundial de 1968, y en muchas otras hasta el día de hoy. En cambio, la segunda fase de la Revolución Rusa, desde 1928 hasta 1953, vinculada a la figura de Stalin, tuvo también un impacto históricouniversal, pero solo de tipo práctico, y además, limitado en su vigencia sólo a la misma vida de Stalin.

Porque Stalin no solo echa atrás y clausura toda la rica y novedosa experiencia del intento de construir una sociedad genuinamente no capitalista en la URSS, sino que también afirma al capitalismo de Estado soviético, a la fallida ideología del "Socialismo en un solo país", y a los también fallidos intentos de imponer a todo el movimiento revolucionario mundial, la abdicación de sus objetivos revolucionarios específicos en cada país, en aras de la supuesta "defensa de la patria socialista". Con lo cual, Stalin cierra el rico y excepcional laboratorio de experimentación anticapitalista soviético del periodo de 1917 a 1928.

Pero es cierto también que es la Unión Soviética estalinista la que salva al mundo de Hitler, contribuyendo de modo decisivo a su derrota final, además de promover en todo el mundo, a través de la Tercera Internacional, la fundación de Partidos Comunistas y el desarrollo de movimientos revolucionarios, a veces de liberación nacional, y en otros casos abiertamente declarados como socialistas o comunistas. Y es por estas dos razones, por las que la Revolución Rusa del periodo estalinista tiene todavía un impacto práctico, no teórico, de alcance histórico-universal, impacto que se apagará con la propia desaparición de Stalin, y con la masiva campaña ulterior de la "crítica al culto de la personalidad".

Y luego de la muerte de Stalin, en 1953, tanto el tercer periodo de la Revolución Rusa, de 1953 a 1989-91, como la etapa actual de la Rusia ya no soviética ni socialista (aunque fuese solo de nombre), sino nuevamente de capitalismo privado y tradicional, son periodos en los que Rusia deja de tener el eco planetario y la irradiación de larga duración de la primera etapa de la Revolución Rusa, e incluso el impacto y presencia mundiales de la segunda etapa, para tener solo un reducido impacto regional entre sus vecinos contiguos y directos, impacto que, en general, tendrá una vigencia solo contemporánea a su propia existencia. Lo que sin embargo no impide, como planteamos antes, que los perfiles actuales de Rusia, aun cuando 
capitalistas privados y tradicionales, son directamente herederos y deudores de la fundamental Revolución Rusa de 1917.

\section{La futura llegada del pasado}

Ya hemos explicado antes lo que, en nuestra opinión, queda todavía vivo y vigente de la Revolución Rusa, y qué pistas suyas pueden ser aún útiles y válidas para los movimientos anticapitalistas actuales. Pues más allá de la Rusia actual, estos movimientos antisistémicos contemporáneos pueden recuperar tanto muchas lecciones aún vigentes de la rica y profunda teoría política leninista, como también muchas enseñanzas aún aplicables, del laboratorio de transformación social anticapitalista soviético de los años de 1917-1927-28. Pero además, y es importante remarcarlo, gracias a la Revolución Rusa y a su herencia, la Rusia actual está más que madura para una nueva Revolución Rusa anticapitalista y antisistémica, una nueva revolución que, acompasándose con otras revoluciones sociales hoy en proceso de germinación en prácticamente todo el planeta, construya en el cercano futuro, no un nuevo intento fallido de "Socialismo en un solo país", sino más bien un espacio local o nacional más, de la lucha antisistémica global genuinamente mundial.

Porque como lo dijo Lenin hace casi cien años, en 1920, "La vida triunfa por encima de todo", y por eso, y vale la pena reiterarlo ahora, a cien años de la importante Revolución Rusa de 1917: "Los comunistas deben saber que, en todo caso, el porvenir les pertenece". Confiemos en que así será.

\section{Referencias bibliográficas}

\section{a) Artículos y capítulos de libros}

Aguirre Rojas, C. A. (1996). "A longa duraçâo: in illo tempore et nunc", en Revista de Historia Das Ideias, № 18, Coimbra.

Aguirre Rojas, C. A. (2011). "Releyendo La guerra civil en Francia desde la América Latina del siglo XXI", en Contrahistorias, № 16.

Aguirre Rojas, C. A. (2017) "Artes, ciencias y saberes neozapatistas: nacer desde abajo el nuevo mundo no capitalista", en Contrahistorias, № 27.

Braudel, F. (1991). "Historia y ciencias sociales. La larga duración", en Escritos sobre historia. México: Ed. Fondo de Cultura Económica.

Wallerstein, I. (2008). "Cuatro acercamientos al neozapatismo mexicano", en Historia y dilemas de los movimientos antisistémicos. México: Ed. Contrahistorias, pp. 214-245. 


\section{b) Libros}

Aguirre Rojas, C. A. (2003). Fernand Braudel e as ciencias humanas. Londrina: Ed. Universidade Estadual de Londrina.

Aguirre Rojas, C. A. (2009). América Latina en la encrucijada. México: Ed. Contrahistorias.

Aguirre Rojas, C. A. (2012). Mandar Obedecendo. As lições políticas do neozapatismo mexicano. Porto Alegre: Ed. Deriva.

Aguirre Rojas, C. A. (2013). Movimenti Antisistemici. Pensare un'alternativa nel XXI Secolo. Roma: Ed. Aracne Editrice.

Aguirre Rojas, C. A. (2014). Antimanuel du Bon Rebelle. Paris: Ed. L'Harmattan.

Aguirre Rojas, C. A. (2015). Retratos para la historia, Ed. Prohistoria, Rosario, 2015.

Bettelheim, C. (1977). Las luchas de clases en la URSS. Primer período (19171923). México: Ed. Siglo XXI.

Bettelheim, C. (1979). Las luchas de clases en la URSS. Segundo período (19231930). México: Ed. Siglo XXI.

Braudel, F. (1978). Las civilizaciones actuales. Madrid: Editorial Tecnos.

Benjamin, W. (2004). Tesis sobre la historia y otros fragmentos. México: Ed. Contrahistorias.

Bloch, M. (1996). Apología para la historia o el oficio de historiador. México: Ed. Fondo de Cultura Económica.

El pensamiento crítico frente a la hidra capitalista. Participación de la Comisión Sexta del EZLN (2015), tomo I. México: Ed. Comisión Sexta del EZLN.

Lenin, V. I. (s/f). Obras Escogidas en Tres Tomos, tomo III. Moscú: Ed. Progreso.

Lenin, V. I. (et al.) (1974). Debate sobre la economía soviética y la ley del valor. México: Ed. Grijalbo.

Marx, C. y F. Engels (2006). Las revoluciones de 1848. México: Ed. Fondo de Cultura Económica.

Preobrazhensky, E. (1971). La nueva economía. México: Ed. Era.

Reich, W. (1970). La revolución sexual. Barcelona: Ed. Ruedo Ibérico.

Semionovich Makarenko, A. (1996). Poema pedagógico. Madrid: Ed. Akal.

Thompson, E. P. (1995). Costumbres en común. Barcelona: Ed. Grijalbo.

Trotsky, L. (1971). El nuevo curso. Problemas de la vida cotidiana. Córdoba: Ed. Cuadernos de Pasado y Presente. 